\title{
Residual Strength and Durability of Glass fiber FRCM and CRM Systems Aged in Alkaline Environments
}

\author{
Valeria Rizzo $^{1}$, Francesco Micelli ${ }^{2}$, Marianovella Leone ${ }^{3}$, Antonio Bonati ${ }^{4}$ and \\ Maria Antonietta Aiello ${ }^{5}$ \\ ${ }^{1}$ Department of Engineering for Innovation, University of Salento, Lecce, Italy, \\ valeria.rizzo@unisalento.it \\ 2 Department of Engineering for Innovation, University of Salento, Lecce, Italy, \\ francesco.micelli@unisalento.it \\ ${ }^{3}$ Department of Engineering for Innovation, University of Salento, Lecce, Italy, \\ marianovella.leone@unisalento.it \\ ${ }^{4}$ National Research Council (CNR), Institute for Construction Technologies (ITC), Viale Lombardia \\ 49, San Giuliano Milanese, 20098, Italy, bonati@itc.cnr.it \\ ${ }^{5}$ Department of Engineering for Innovation, University of Salento, Lecce, Italy, \\ antonietta.aiello@unisalento.it
}

\begin{abstract}
Fabric Reinforced Cementitious Matrix (FRCM) and Composite Reinforced Mortar (CRM) systems are used as Externally Bonded Reinforcements (EBR) in civil and historical construction. These materials are made by fibrous reinforcement, in forms of dry (FRCM) or cured (CRM) meshes embedded in a cementitious/hydraulic lime matrix. At present, this technology is considered very promising in the field of structural strengthening, retrofitting and repair existing structures. This is true especially in those cases of masonry and historical buildings, due to the specific criteria of conservation and compatibility with the substrate that need to be fulfilled. These materials, in fact, results more compatible with masonry substrate because of the inorganic matrix, instead of polymeric resin used for the well-known FRP systems (Fiber Reinforced Polymers). The recent use of these new materials in civil engineering needs appropriate and complete guidelines, that regard not only the design aspects but also the durability features. This paper presents the results of a large experimental program focused on the durability of FRCM and CRM systems and their single components, in different alkaline environments. For the whole experimental campaign, the samples have been immersed into three different alkaline solutions, for four exposure times (500, 1000, 2000 and $3000 \mathrm{hrs}$ ). In addition, in order to study the different accelerating effects due to temperature, three different temperatures were maintained during the ageing periods: $23^{\circ} \mathrm{C}, 40^{\circ} \mathrm{C}$ and $70^{\circ} \mathrm{C}$. The results about the mechanical characterization of residual properties are discussed in order to highlight the influence of alkaline environments on the mechanical properties of single elements and the whole strengthening systems that were tested herein.
\end{abstract}

Keywords: Durability, FRCM, CRM, Alkaline Environments, Accelerated Aging.

\section{Introduction}

Masonry buildings are a significant part of the architectural heritage in Europe and all over the world. A large number of these buildings, in consequence of earthquakes or other degradation processes, require repair and reinforcement because of their high seismic vulnerability and brittleness. In the last 20 years, innovative systems called EBR (Externally Bonded Reinforcement) became a common strengthening solution to replace the ordinary techniques and traditional materials in retrofitting of existing buildings. EBRs are typically composite materials, constituted by fibers of various nature (carbon, steel, basalt, glass, aramid or natural 
fiber) embedded in a matrix. The most common systems are known as FRP (Fiber Reinforced Polymers), in which the matrix is constituted by a polymeric thermoset resin. During the last years, a new generation of fibrous materials was conceived and designed, by replacing the polymeric resin with inorganic matrix. These materials are called FRCM (Fabric Reinforced Cementitious Matrix) or CRM (Composite Reinforced Mortar). The difference between them is that in FRCM a soft dry net of fibers constitutes the internal reinforcement, while in CRM a rigid FRP grid is used as internal reinforcement embedded in a cementitious or lime mortar. This last technique can be considered a replacement of the traditional reinforced plaster, in which steel grid is replaced by FRP mesh. The mortar-based strengthening materials represent a valid alternative to the well-known FRP in those cases of reinforcement of existing masonry buildings. In fact, FRCMs and CRMs ensure compliance with the requirement for the conservation of architectural heritage (ICOMOS/ISCARSAH 2005). The application of FRCM and CRM provides a better compatibility with masonry substrates because of the high vapor permeability of mortar, but not only. In fact, these materials are sustainable and reversible, can be easy applied also on irregular substrates, on wet support and have better performance at elevated temperature. Due to the low costs, to the absence of galvanic corrosion (as same as traditional composites) and to the installation requirements that recall the traditional mortars, the interest of many researcher was addressed to these materials. However, many issues still require further investigation in order to guarantee the effectiveness of this technique. In fact, for both types of inorganic EBR systems, the investigation on short- and long-term behavior is essential. The durability long-term behavior of the lack of experimenta degradation mechanisn technical literature abou 2014; Nobili and Sighorini 2017; Donnini et
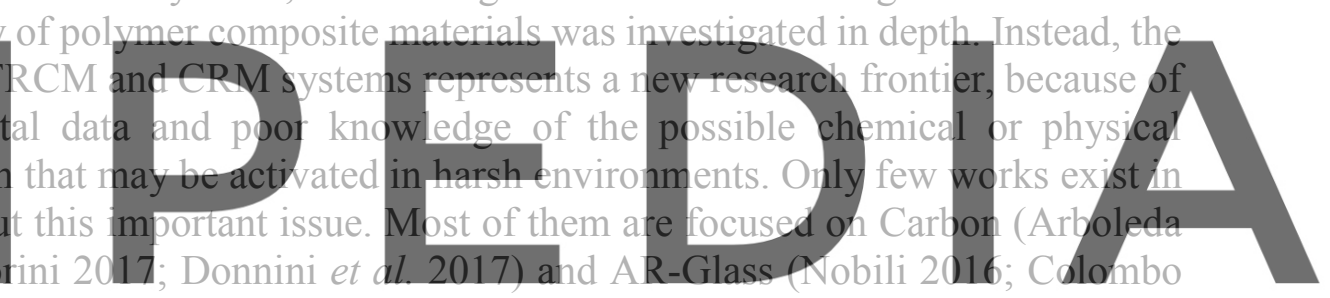

et al. 2011) FRCM, in some cases following the procedures defined by Acceptance Criteria

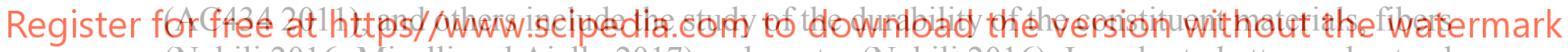
(Nobili 2016; Micelli and Aiello 2017) and mortar (Nobili 2016). In order to better understand all the possible effects due to aggressive environments in which these external reinforcement systems may work during the service lifetime, a large experimental program is presented in this paper. The research was focused on the durability of FRCM and CRM systems and their single components, namely dry glass fibers, pre-cured glass fiber grids and mortar matrix, in alkaline environments. In fact, it is important to investigate in depth, not only the behavior of the entire system, but also the effects on the chemical, physical and mechanical properties of constituents. The obtained results, in terms of residual mechanical properties and physical damages, are discussed in the paper in order to highlight the influence of alkaline environments on the mechanical properties of the tested specimens.

\section{Materials and Method}

The experimental program for the determination of FRCM/CRM's mechanical properties after alkaline attack consisted of two different groups. The first, called System 1 is a FRCM reinforcement while the second one, labelled System 2, is a CRM material. For both groups, not only the systems have been considered, but also their constituent elements (matrix and 
reinforcement). For System 1, in fact, FRCM, dry grid of AR (alkali-resisted) glass fiber and mortar samples have been tested. The System 2 consists only of dry yarns and the corresponding pre-cured mesh of E-CR (electric grade) glass fibers reinforced polymer (GFRP), utilized to make CRM.For both groups, the alkaline treatments had been performed by immersing the samples in three different alkaline solutions, varying the chemical ions and the $\mathrm{pH}$ values. The first solution, called A, wanted to simulate the lime mortar matrix, with a $\mathrm{pH}$ equal to 12.6 (Micelli and Aiello 2017). The solution B, corresponding to Portland matrix, is a saturated solution of $0.16 \% \mathrm{Ca}(\mathrm{OH})_{2}+1 \% \mathrm{Na}(\mathrm{OH})+1.4 \% \mathrm{~K}(\mathrm{OH})$ in weight, achieving a $\mathrm{pH}=12.8$ (Litherland et al. 1998; Micelli and Aiello 2017). The last one, solution C, follows the standard protocol (ASTM D7705/D7705M - 12 2015), with the highest $\mathrm{pH}$ equivalent to 13.8. Four periods of treatment are considered, i.e. 500, 1000, 2000 and 3000 hours. In addition, with the aim to accelerate the ageing, the solutions were maintained at three incremental temperatures, $23^{\circ} \mathrm{C}, 40^{\circ} \mathrm{C}$ and $70^{\circ} \mathrm{C}$. The samples have been labeled using the following alphanumeric code: first part means the type of specimens (for System 1 DG=Dry Grid, M=mortar, FRCM=Fabric Reinforced Cementitious Mortar; for System 2 GG=GFRP Grid, DY=Dry Yarn); second part states for treatment temperature (U=Untreated sample, $\left.23,40,70^{\circ} \mathrm{C}\right)$; third letter distinguishes the alkaline environments ( $\mathrm{A}=$ lime solution, $\mathrm{B}=$ Portland solution, $\mathrm{C}=$ standard alkaline solution); fifth part sets out the ageing time (500, 1000, 2000, 3000 hrs.). The whole experimental program consisted of 824 samples, of which: 23 untreated specimens, i.e. 5 samples for DG U, FRCM U, DY U, GG U and 3 samples for M U); 801 aged specimens, i.e. 5 samples for each type of materials excluded mortar M (3 samples), for each alkaline environment, for each temperature and for ead
samples, that constitutec the reference ones, ha
Single yarns of DG_U materials, i.e. the in
have been cut from the dry grid, obtaining sa
direct tensile tests. The mechanical properties $1373 \mathrm{MPa}(\mathrm{CoV}=9 \%$ ); maximum strain, Ef,DG, $1.6 \%$ (CoV=4\%); elastic modulus, Ef,DG, $91 \mathrm{GPa}$

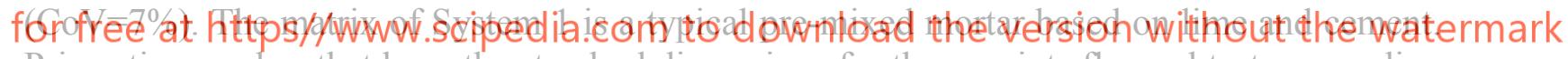
Prismatic samples, that have the standard dimensions for three-points flexural tests, according to (CEN 1999 1999), i.e. 40x40x160 mm, have been tested for three-point bending test and the flexural strength has been determined. The compression test was carried out on the two parts of each mortar prisms derived from the flexural tests. A maximum compressive stress, $f_{c, M}$, of 20.6 $\mathrm{MPa}(\mathrm{CoV}=7 \%)$ and a maximum flexural stress, $f_{f, M}$, of $4.0 \mathrm{MPa}(\mathrm{CoV}=12 \%)$ were experimentally measured for the mortar. The reinforced system was made by one sheet of DG embedded in $10 \mathrm{~mm}$ of mortar. Two thin layers of water-based adhesion promoter were applied before and after the introduction of the glass fabric, as recommended by the manufacturer. The

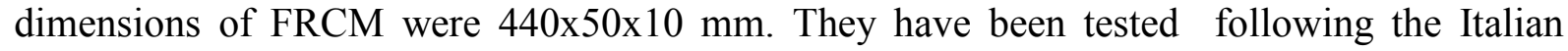
guidelines (Consiglio Superiore dei Lavori Pubblici 2018) and the mechanical properties obtained are: ultimate stress, $\sigma_{u, F R C M}=1632 \mathrm{MPa}(\mathrm{CoV}=16 \%)$ and corresponding maximum strain $\varepsilon_{u, F R C M}=1.3 \%(\mathrm{CoV}=29 \%)$. For the second group of specimens, a pre-cured mesh of glass fibers reinforced polymer (i.e. GFRP grid) and the dry glass yarns have been tested, carrying out tensile test in both cases. The mechanical properties of GG samples result the follows: elastic modulus, $\mathrm{E}_{\mathrm{f}, \mathrm{GG}}, 48 \mathrm{GPa}(\mathrm{CoV}=6 \%)$; tensile strength, $\sigma_{\mathrm{f}, \mathrm{GG}}, 1485 \mathrm{MPa}$ $(\mathrm{CoV}=5 \%)$; the corresponding strain, $\varepsilon_{\mathrm{f}, \mathrm{GG}}$, is $3,0 \%(\mathrm{CoV}=8 \%)$. The dry yarns $\mathrm{DY}$, that are used to manufacture the GFRP grid (GG), have been characterized, according to the Italian 
technical standard. The ultimate tensile force, obtained from tensile test, was equal to $617.2 \mathrm{~N}$ $(\mathrm{CoV}=10 \%)$ and the elongation at break resulted $19.1 \mathrm{~mm}(\mathrm{CoV}=19 \%)$. To immerse samples in the three different alkaline solutions, ad-hoc supports have been designed and fabricated, in order to promote a uniform distribution of the ageing solutions. All samples have been located into different stainless steel containers with transparent and plastic lid, for each alkaline solution and for each temperature.

\section{Experimental Results and Discussions}

After each curing period, DG, FRCM, DY and GG samples have been tested by performing direct tensile tests, while for mortar specimens (M) both three-points flexural test and compressive test have been carried out. In this way their principal mechanical properties have been determined and compared with those of control specimens. In the following section, a synthesis of the numerous outcomes has been reported.

\subsection{G Samples}

The stress vs strain behavior of glass fibers yarns was pseudo-linear. At high loads, prior to failure, in some cases, sudden discontinuities were found in the curves. This was due to the progressive rupture of single filaments. In fact, the failure mode (Figure 1a) was characterized by a gradual tensile rupture of single filaments of the yarns, regardless of the alkalinity of the solution or the immersion time. With the increment of the temperature, the alkalinity of the

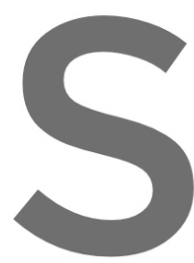
solution C has caused th for the solution B the temperature, i.e. $70^{\circ} \mathrm{C}$ different alkalinity of th regard to the treatments
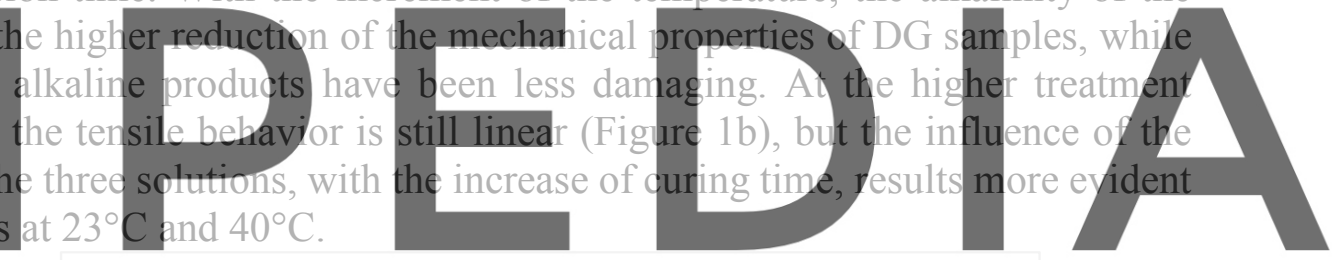

Register for free at https//www.scipedia.coln to download the version without the watermark

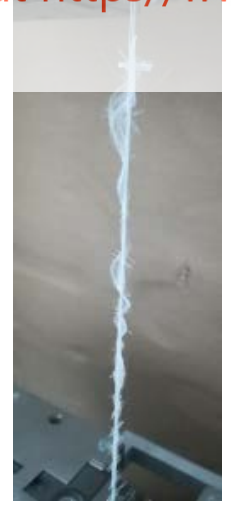

(a)

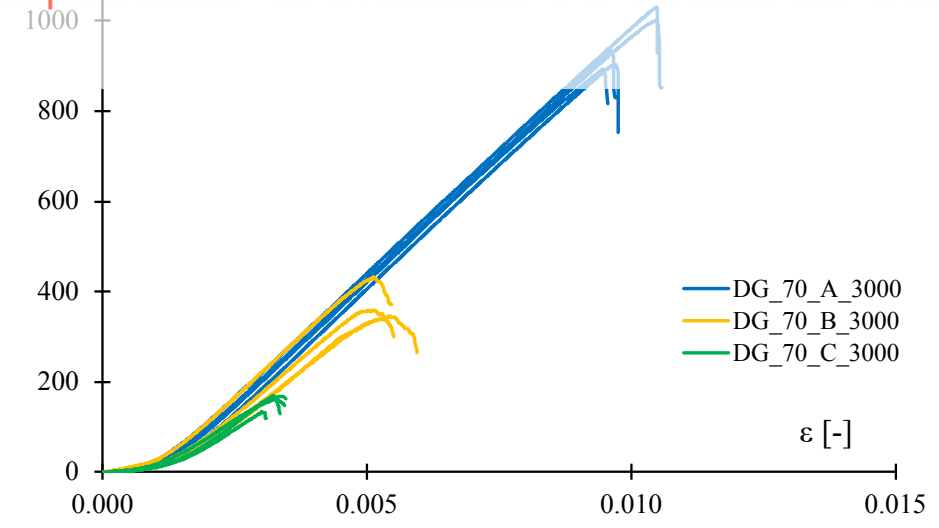

(b)

Figure 1. Typical failure mode of DG samples (a) and an example of stress-strain curves, for specimens aged at $70^{\circ} \mathrm{C}$ after 3000 hours (b). 


\subsection{Samples}

For mortar samples, the solution B turned out to be the most aggressive alkaline environment. The detrimental effects of its alkaline ions $\left(\mathrm{Ca}^{2+}, \mathrm{Na}^{+}\right.$and $\left.\mathrm{K}^{+}\right)$are improved by the high temperature, causing the loss of compressive strength equal to $88 \%$, after 125 days of treatments (Figure 2b). For shorter period of immersion, the reduction of the mechanical properties was obviously less (Figure 2a). In this case, after an immediate decrease of both flexural and compressive strength of mortar, no matter the alkalinity level, the immersion in aqueous solutions allows the delayed hydration of inorganic matrix and its self-healing. This results into a slight ascent of mechanical properties.

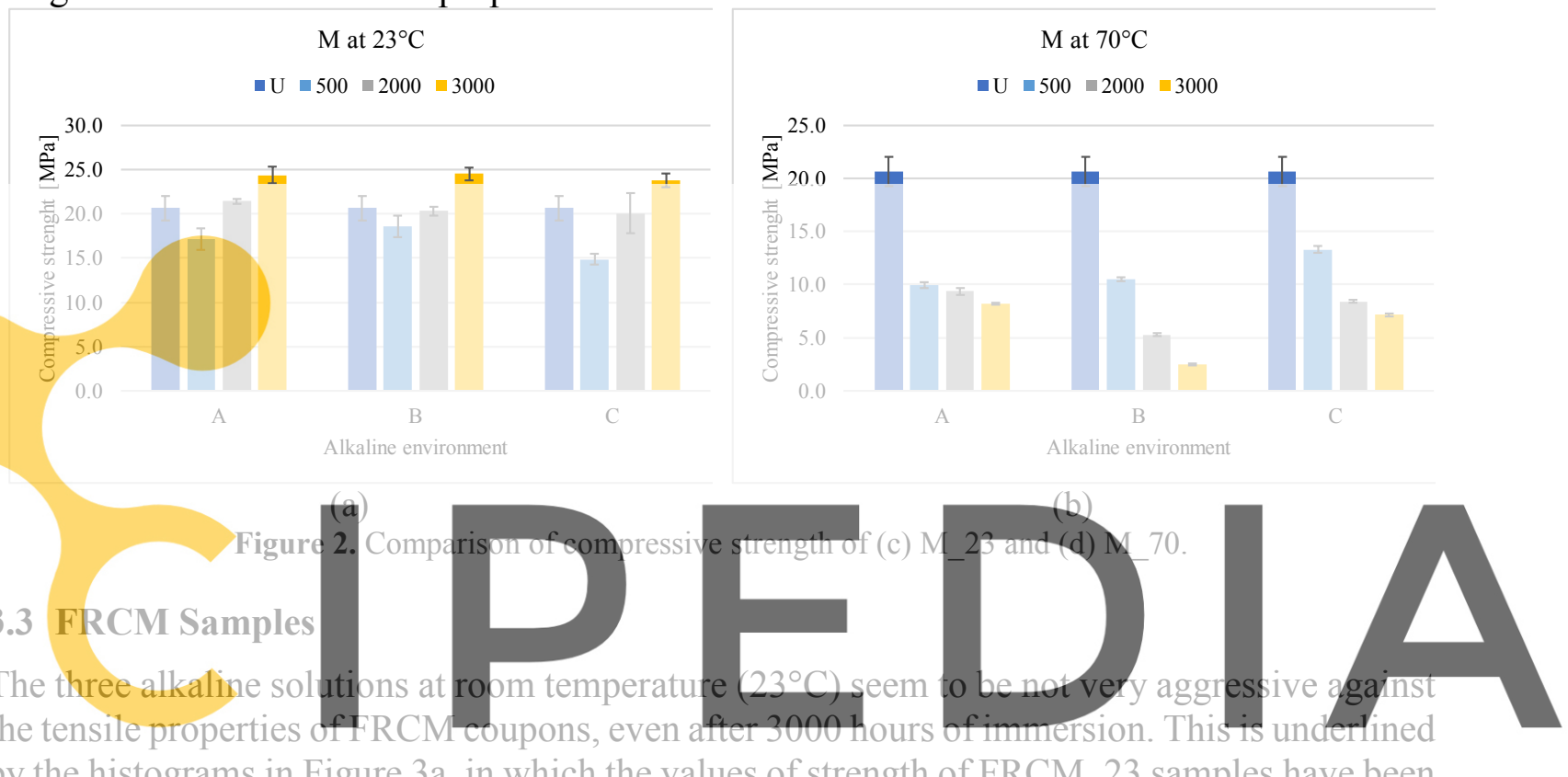

by the histograms in Figure 3a, in which the values of strength of FRCM 23 samples have been

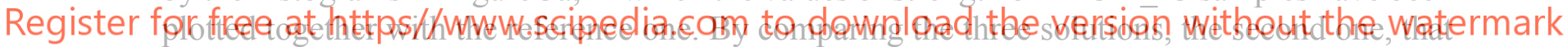

reproduces the Portland cement, has caused the greater damaging effects on the treated specimens, but, even in this case, they are very limited. The behavior of samples resulted more deformable but also more brittle. The formation of the first crack in the matrix often corresponds to the ultimate condition of samples cured for longer time. In fact, very few cracks predict the tensile failure of glass yarns.

\subsection{DY Samples}

The decay of mechanical features of DY specimens, contrary to what obtained from mechanical tests on dry glass fabric (DG), was activated to room temperature as early as 500 hours. This could be related to the different nature of glass fibers. Indeed, DG are constituted of alkaliresistant (AR) glass fibers, that are made by a specific formulated glass composition with addition of Zirconia $\left(\mathrm{ZrO}_{2}\right)$, and they are suitable for use in inorganic matrix. On the other hand, DY consist of the ordinary electrical grade glass fibers (E-glass). This kind of fibers are a low alkali glass, without any inclusion of Zirconia and then they are prone to chemical degradation in presence of alkaline species. The evident degradation of DY samples is due to a combination of mechanisms which may occur within the microstructure of the composite materials, i.e. an 
effect of the ions $(\mathrm{OH})^{-}$, which produces corrosion of the fibers, and a second effect due to the precipitation of hydration products, which may reduce the flexibility of the fibers (Bentur 2000; Majumdar, West, and Larner 1977). All of this has been evident carrying out SEM (Scanning Electronic Microscope) analysis on damaged glass filaments. Figure $4 a-b$, which relate to specimens treated with CVD (Chemical Vapor Deposition) of gold particles (O'Brien 2001), show the typical morphology of the etching on the glass surface, as also seen by (Guo et al. 2018) in glass and basalt, and by (Aghamohammadi et al. 2018) in basalt fibers. In the present case, the attack appeared more extensive due to the extreme ageing conditions adopted by enhancing the temperature up to $70^{\circ} \mathrm{C}$.

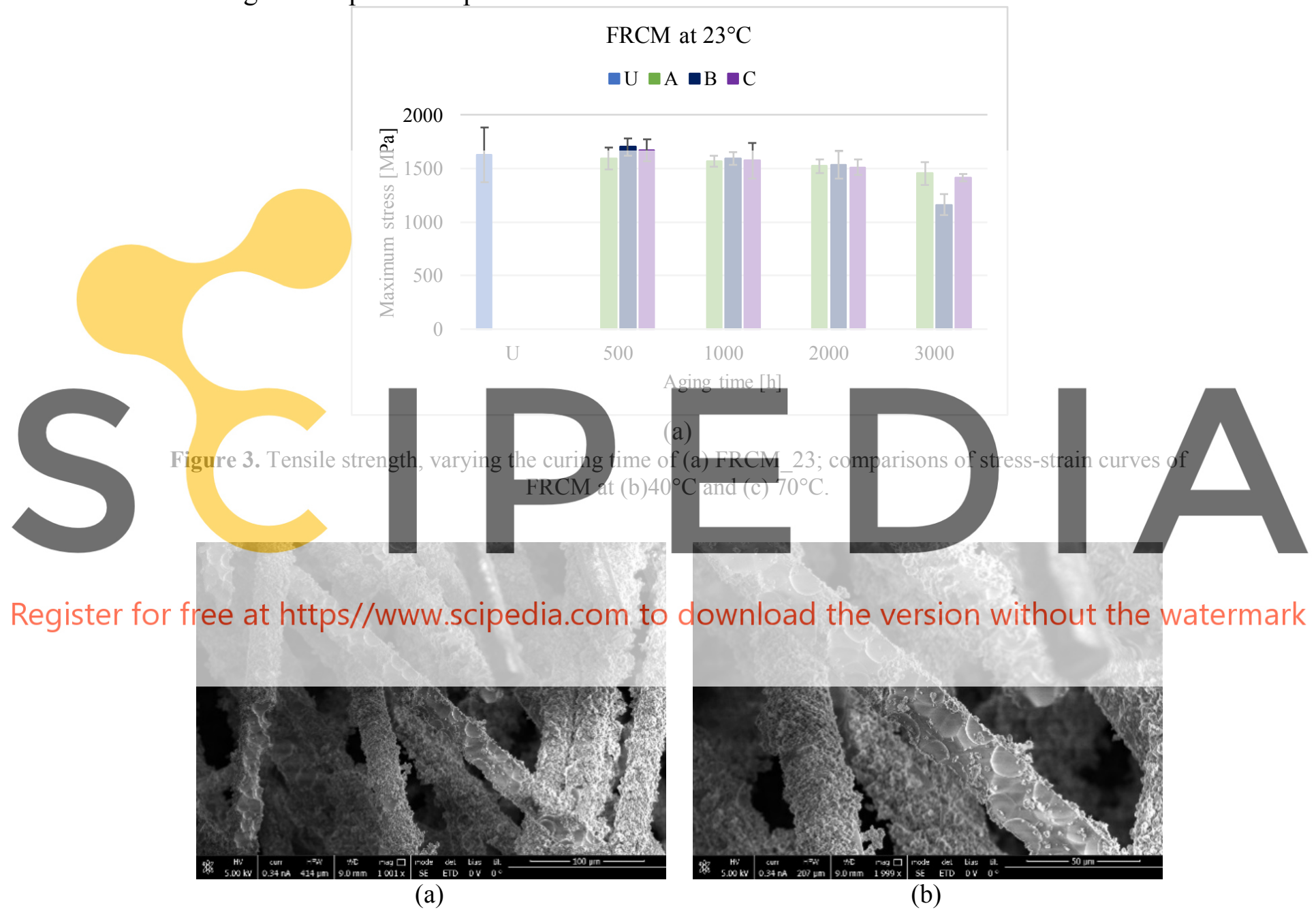

Figure 4. Images of DY_70_A_3000 specimen with (e) 1001x, (f) 1999x of magnification.

\subsection{GG Samples}

As underlined by the histograms in Figure 5a, the most aggressive treatment is constituted by the solution B: $\sigma$ decreases drastically already after 500 hours of immersion at $23^{\circ} \mathrm{C}$ (decline of $20 \%$ ). As expected, higher temperature accelerates the detrimental effect of ions dissolved into the solution and the gap between the mechanical feature of reference samples and 
GG_40_B_3000 is more that $80 \%$ (Figure 5b). The different between the maximum tensile stress of untreated samples (blue column) is more than $95 \%$ for samples treated at $70^{\circ} \mathrm{C}$. For the two other solutions, $\mathrm{A}$ and $\mathrm{C}$, the reduction does not exceed the range of variability of the standard deviation, for treatments at standard temperature, while increase at the highest temperature (-77\% and $-73 \%$ for the solution $\mathrm{A}$ and $\mathrm{C}$ respectively), however less than in case for solution B.
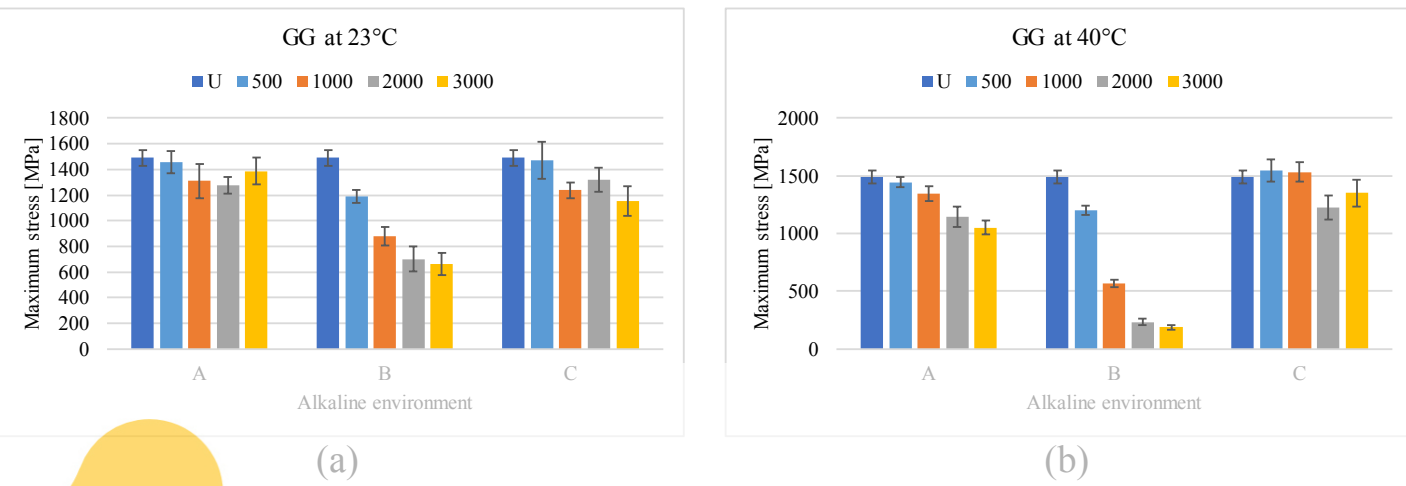

Figure 5. Maximum tensile stress, varying the solutions of GG_23, GG_40

\section{Conclusions}

In the present paper, a large experimental program on long-term behavior of composite systems has been briefly reported. treated into three differ 3000 hrs.). The ageing $70^{\circ} \mathrm{C}$. The outcomes systems highlighted what i Aging at $23^{\circ} \mathrm{C}$ results ent Two groups of sampaline conditions
was accelerated by inci
the mechanical charact
at in the follow:
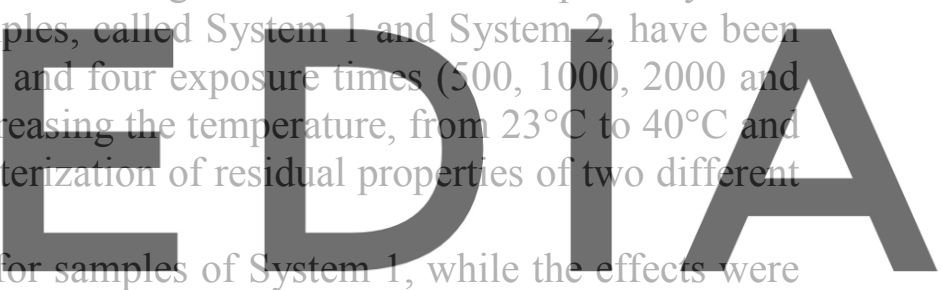
more visible for dry yarns of E-glass fibre and the GFRP specimens (System 2)

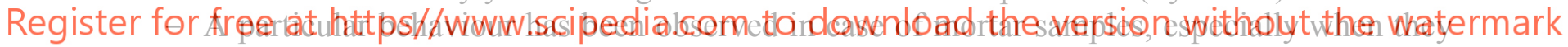
have been aged at $23^{\circ} \mathrm{C}$. The immersion in an aqueous solution leads to self-healing process and the mechanical properties do not decrease because of the alkaline environments, but rather increase as effect of the delayed hydration of inorganic matrix.

- The treatments at $70^{\circ} \mathrm{C}$, as expected, have provoked an extremely detrimental impact and until the completely break-up of the E-glass dry yarns.

- For these last samples SEM analysis has been performed, in order to detect the surface morphologies and fracture surface of E-glass corrupted filaments. In particular, in case of solution $\mathrm{A}$, at $70^{\circ} \mathrm{C}$ and after 3000 hours of immersion, the filaments result completely covered by precipitated calcium carbonate and the massive damage that occurred have caused an evident reduction of the cross section, almost to zero in some regions. This is due to etching on the glass surface and to the extreme ageing conditions adopted by enhancing the temperature up to $70^{\circ} \mathrm{C}$.

\section{Acknowledgements}

The authors would like to acknowledge the support of the staff of the Fibre Net S.p.A and of the Construction. Division of the National Research Council (CNR) for their strong support in developing the ongoing research. The support of the RELUIS Project 2019-21 is strongly appreciated too. 


\section{ORCID}

Valeria Rizzo: https://orcid.org/0000-0003-1267-7484

Francesco Micelli: https://orcid.org/0000-0002-1751-7343

Marianovella Leone: https://orcid.org/0000-0001-9929-6785

Antonio Bonati: https://orcid.org/0000-0002-7221-6180

Maria Antonietta Aiello: https://orcid.org/0000-0001-6533-7008

\section{References}

AC434. 2011. “ACCEPTANCE CRITERIA FOR MASONRY AND CONCRETE STRENGTHENING USING FIBER-REINFORCED CEMENTITIOUS MATRIX (FRCM) COMPOSITE SYSTEMS.”

Aghamohammadi, Hamed, S. Navid Hosseini Abbandanak, Reza Eslami-Farsani, and S. M.Hossein Siadati. 2018. "Effects of Various Aluminum Surface Treatments on the Basalt Fiber Metal Laminates Interlaminar Adhesion." International Journal of Adhesion and Adhesives 84 (February): 184-93. https://doi.org/10.1016/j.ijadhadh.2018.03.005.

Arboleda, D. (2014). "Fabric Reinforced Cementitious Matrix (FRCM) Composites for Infrastructure Strengthening and Rehabilitation : Characterization Methods" PhD Thesis, 1-131.

ASTM D7705/D7705M - 12. 2015. "Standard Test Method for Alkali Resistance of Fiber Reinforced Polymer ( FRP ) Matrix Composite Bars Used in Concrete Construction” i: 1-5. https://doi.org/10.1520/D7705.

Bentur, A. (2000). "Role of Interfaces in Controlling Durability of Fibre-Reinforced Cements." J. Mater. Civ. Eng. 12 (February): 2-7.

CEN (1999). 1999. "EN 1015-11: Methods of Test for Mortar for Masonry - Part 11: Determination of Flexural and Compressive Strength of Hardened Mortar." European Committee for Standardization, 12. http://www.docin.com/p-279781425.html.

Colombo, I., Colombo, M., Magri, A., Zani, G. and di Prisco, M. (2011). "Textile Reinforced Mortar at High Temperatures." Applied Mechanics_ and Materials 202-7. https://doi.org/10.4028/w

Consiglio Superiore dei Lav Controllo Di Accettazion Consolidamento

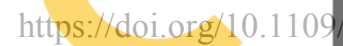

Donnini, J., De Caso, F.
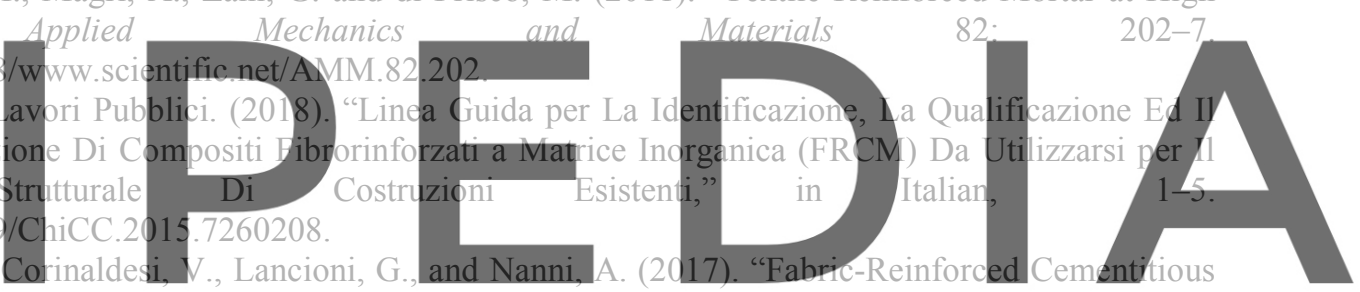
Matrix Behavior at High-Temperature: Experimental and Numerical Results." Composites Part B 108: 108-

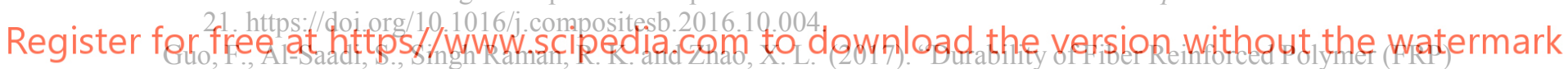
in Simulated Seawater Sea Sand Concrete (SWSSC) Environment." Corrosion Science 141: 1-13. https://doi.org/10.1016/j.corsci.2018.06.022.

ICOMOS/ISCARSAH. (2005). "Recommendations for the Analysis, Conservation and Structural Restoration of Architectural Heritage" 2005. https://www.icomos.org/en.

Litherland, K.L., Oakley, D.R. and Proctor, B.A. (1981). "The use of accelerated aging procedures to predict the long term strength of GRF composites". Cem Conc Res 1981;11: 455-466.

Majumdar, A. J., J. M. West, and L. J. Larner. (1977). "Properties of Glass Fibres in Cement Environment." Journal of Materials Science 12 (5): 927-36. https://doi.org/10.1007/BF00540975.

Micelli, F., and Aiello, M.A. (2017). "Residual Tensile Strength of Dry and Impregnated Reinforcement Fibres after Exposure to Alkaline Environments." Composites Part B: Engineering. https://doi.org/10.1016/j.compositesb.2017.03.005.

Nobili, A. (2016). "Durability Assessment of Impregnated Glass Fabric Reinforced Cementitious Matrix (GFRCM) Composites in the Alkaline and Saline Environments." Construction and Building Materials 105: 465-71. https://doi.org/10.1016/j.conbuildmat.2015.12.173.

Nobili, A, and Signorini. C. (2017). "On the Effect of Curing Time and Environmental Exposure on Impregnated Carbon Fabric Reinforced Cementitious Matrix (CFRCM) Composite with Design Considerations." Composites Part B 112: 300-313. https://doi.org/10.1016/j.compositesb.2016.12.022.

O’Brien, P. (2001). "Chemical Vapor Deposition.” In Encyclopedia of Materials: Science and Technology, 117376. Elsevier. https://doi.org/10.1016/B0-08-043152-6/00219-9. 